\title{
Observations on Non-Maturing Redfish (Sebastes mentella Travin) in the Northwest Atlantic
}

\author{
F.M. Troyanovsky \\ Scientific-Industrial Association "Sevrybpoisk" \\ 7 Papanin Street, 183012, Murmansk, Russia
}

\begin{abstract}
In the early-1960s a deepwater form of redfish (Sebastes mentella Travin) was found at depths more than $500 \mathrm{~m}$ on the continental slopes of Labrador and North Newfoundland. This group differed from the beaked redfish commonly distributed in these areas by the biological peculiarities of non-developed reproductive organs and lack of sexual dimorphism. The results of nearly 30-year observations showed that the form of non-maturing redfish had not changed. They were distributed along the continental slope northward of Div. 3K and the fish size increased from north to south. The distribution of this form of redfish was similar to that of non-maturing roundnose grenadier (Coryphaenoides rupestris). The origin and causes which led to inhibition of gonadal development of both groups were considered to be analogous. The non-maturing group of redfish was thought to originate from partial eggs and larval drifts from the Irminger Sea to form a pseudo-population in the area studied. The need for studies of the population and its exploitation of this potentially commercially valuable group is emphasized.
\end{abstract}

\section{Introduction}

Nearly three decades ago an unusual deepwater form of the redfish (Sebastes mentella Travin) was found on the continental slopes of Labrador and North Newfoundland during the USSR research vessel surveys in the area. These differed from the beaked redfish commonly distributed in these areas by some biological peculiarities; they did not develop sexually and they lacked sexual dimorphism. In recognition of the potential commercial importance of this group of fish, data were collected on them through the next 2 decades.

To-date, very little is known about these redfish, and their commercial value is not yet estimated. On the basis of the long-term observations in this study, we attempt to describe our understanding of this non-maturing form of redfish and present a hypothesis to describe the formation of the group.

\section{Materials and Methods}

Data used for this study were collected during USSR research vessel cruises in the areas of the continental slope of the Northwest Atlantic through the period 1964-84. Survey locations and published literature were used to study migration and distribution patterns. Data on vertical distribution of nonmaturing redfish were derived from the trawl catches taken from different depths. The fish caught in the various cruises received the standard treatment for biological observations. When the unusual form was encountered, they were tested against the length-age keys, commonly used for stock assessment of beaked redfish in NAFO (see assessment reports in NAFO Sci. Coun. Reports series). The reproductive organ development, peculiarities of feeding and meristic characteristics were then also studied. More than 30000 fish were examined during the study.

\section{Results and Discussion}

In the early-1960s the unusual group of redfish was found at a depth range of $500-700 \mathrm{~m}$ in NAFO Div. $2 J+3 K$. As far as the external features, growth rates and age composition were concerned, this group did not practically differ from the redfish $S$. mentella, inhabiting the shallower depths of the same region. However, all the fish, even the very old fish, were found to be immature. In addition, adult males and females lacked sexual dimorphism; that is they did not show the usual characteristic of mature males being smaller than females of the same age. It was probable that the deepwater redfish did not make vertical daily migrations to a great extent as was indicated by catches taken in Div. 3K during day-time and at night being approximately even in size (Pechenik and Troyanovsky, 1970; Voss and Draffehn, 1963). This fish group with the sexually non-maturing condition apparently also did not perform the characteristic migrations from shallower waters to greater depths as is done by the beaked redfish of this region in relation to their post-larval distribution and the sexual maturation period of the adults.

In samples of subsequent years, groups of these non-maturing redfish were found in Div. $2 \mathrm{G}$ and $2 \mathrm{H}$ not far from Baffin Island and extending to the continental slope off West Greenland. According to 
our observations and data of other authors (Zakharov and Chekhova, 1972; Templeman, 196I) the length compositions showed some trend of an increase in size from north to south. We propose this trend was indicating the existence of a one-way migration, although other biotic and abiotic factors must necessarily be evaluated.

In samples from Div. 3K, the non-maturing redfish were absent. This allowed us to assume that the southern region of Subarea 2 is the margin of the distribution area of non-maturing redfish.

In our earlier considerations, it was thought that the non-maturing redfish could be a hybrid form derived from natural crossing of $S$. mentella and $S$. marinus, and that the hybridization resulted in disturbances of sexual development and functions (Sidorenko, 1967). However, the more extensive data collected subsequently showed, that this nonmaturing redfish inhabited a number of areas where there were no S. marinus. This excluded the possibility of hybridization.

On the other hand it was observed, that the distribution of these non-maturing redfish in the Northwest Atlantic was similar to the areas inhabited by the roundnose grenadier, (Coryphaenoides rupestris Gunnerus) which also exhibits the sexually non-maturing characteristics in the same way. The reasons for the non-maturing of the $C$. rupestris in the Northwest Atlantic have recently been explained adequately as being related to the egg and larval drift with ocean currents. Drifts of partial groups of eggs and larvae from the main spawning grounds on the Mid-Atlantic Ridge have been described as the origin of these non-maturing roundnose grenadier (Dushchenko and Savvatimsky, 1987), and the reason that at early stages of life they drifted under unfavourable cold conditions is attributed to the changes which occurred in the organisms to inhibit gonad development.

Having observed ecological similarity between the non-maturing roundnose grenadier of the Northwest Atlantic and the non-maturing redfish, we suggest the following hypothesis for the non-maturing redfish: Apparently the ways and the causes for transport of this fish into the Northwest Atlantic and also the physiological changes in the organisms have the same origin. The main area from which the transport of redfish takes place is most probably the Irminger Sea, where the spawning grounds of redfish overlap or border on the spawning grounds of the roundnose grenadier (Fig. 1). Thus, it is probable that the groups of non-maturing deepwater redfish in the Northwest Atlantic are a component of the population of the redfish of the Irminger Sea.

Analysis of the materials on biogeography indicates that independent (self-reproducing) redfish

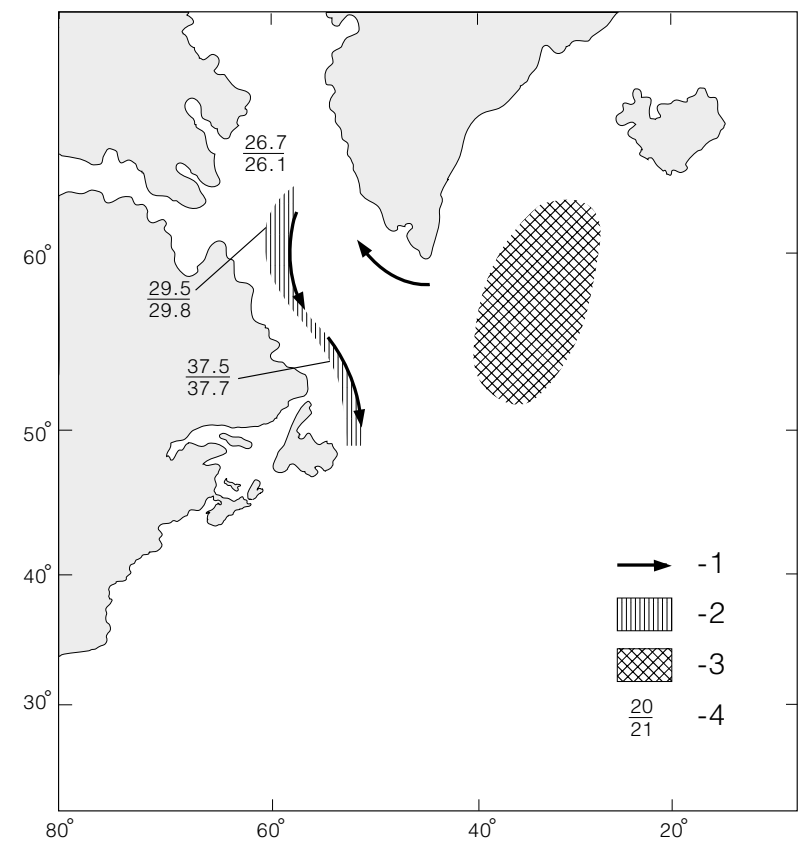

Fig.1. Distribution chart of non-maturing redfish (Sebastes mentella Travin) in the Northwest Atlantic:

1. Tracks of transport of larvae and young fish into the Northwest Atlantic.

2. Areas of inhabitation of adult fish.

3. Spawning grounds of redfish and roundnose grenadier.

4. Mean length $(\mathrm{cm})$ of non-maturing redfish (males are in numerator, females are in denominator).

populations inhabit waters with closed circulation, and those providing favourable conditions for fish survival at all stages of life. It is obvious that the population of the Irminger Sea redfish is complex, and consists of a system of populations related to such circulations genetically. Fish transported out of the circulation limits into the Northwest Atlantic, with the help of the Irminger Current, would then form an independent population. Due to the inhibited development of gonads and absence of reproductive capabilities, this population according to the Beklemishev's classification (Beklemishev, 1969) should be considered to be a pseudo-population. The distribution of this pseudo-population as indicated by our samples is from the Greenland-Canada border in Subareas 0 and 1 to Div. 3K, and the area may be described as a sterile zone of emigration.

It is apparent that the pseudo-population of non-maturing redfish exists as a result of transport from other areas, and does not mix with local normally developing populations. It is also evident that the group is not able to reproduce and thus population growth is only through immigration. It is therefore necessary that separate investigations be carried out to study the state of stocks and the effects 
they experience through exploitation. To our knowledge neither research programs on redfish nor the fisheries on redfish differentiate these non-maturing fish from the rest of the redfish populations. It should be taken into account that the exploitation rate of non-maturing redfish can be greater compared to the other fishes, because its exploitation does not affect the reproductive capacity of the population. This is especially important for Subarea 2 where the non-maturing redfish is most abundant and likely to have commercial value.

The material is presented primarily to demonstrate the importance of this ecological isolation of the redfish of the Irminger Sea and to propose the possible effects of the Irminger Current on the redfish stocks. A better understanding of the processes can help in precise modelling of the population.

\section{References}

BEKLEMISHEV, K.V. 1969. Ekologiya i biogeografiya pelagiali. M:Nauka, $287 \mathrm{p}$.
DUSHCHENKO, V.V., and P.I. SAVVATIMSKY. 1987. The intraspecific structure of the roundnose grenadier, Coryphaenoides rupestris Gunnerus, in the North Atlantic: variability in local groups and conditions for their forming. Vopr. Ikhtiol., 5: 784-793.

PECHENIK, L.N., and F.M. TROYANOVSKY. 1970. Resource base for trawl fishing on the continental slope of the North Atlantic. Syryevaya baza rybolovstva na materikovom sklone Severnoy Atlantiki. Murmansk, p. 53-57.

SIDORENKO, I.N. 1967. Distribution of beaked redfish Sebastes mentella Travin at different depths on the North Newfoundland Bank. Mater. Rybokhoz. Issled. Sev. Bass., 8: 166-177.

TEMPLEMAN, W. 1961. Redfish distribution off Baffin Island, Northern Labrador and Ungava Bay in August - September 1959. ICNAF Spec. Publ., 3: 14-21.

VOSS, J., and P. DRAFFEHN. 1963. Vorlaufiger Bericht uber die Durchfuhrung einer kommerziellen Fischerei in 600 bis $800 \mathrm{~m}$ Wassertiefe vor NewfoundlandLabrador. Fischerei-Forschung, Heft 1,S.25-28.

ZAKHAROV, G.P., and V.A. CHEKHOVA. 1972. Distribution and biological characteristics of beaked redfish of the Davis Strait. Trudy PINRO, Murmansk, 28: 184-198. 
